\title{
Conformational signature of Ishikawa's reagent using NMR information from diastereotopic fluorines
}

\author{
Laize A. F. Andrade ${ }^{1}$, Lucas A. Zeoly ${ }^{2}$, Rodrigo A. Cormanich ${ }^{2}$ and Matheus P. Freitas ${ }^{* 1}$
}

Full Research Paper

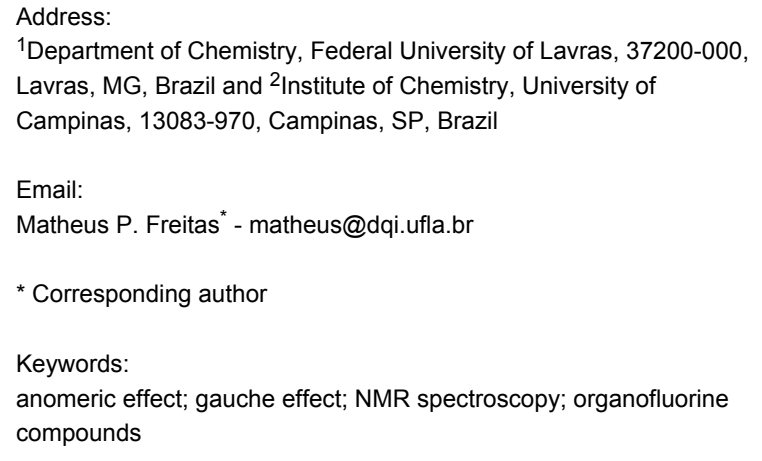

\author{
Beilstein J. Org. Chem. 2019, 15, 506-512. \\ doi:10.3762/bjoc. 15.44 \\ Received: 14 December 2018 \\ Accepted: 13 February 2019 \\ Published: 20 February 2019 \\ Associate Editor: P. Schreiner \\ (C) 2019 Andrade et al.; licensee Beilstein-Institut. \\ License and terms: see end of document.
}

\begin{abstract}
The active species of the Ishikawa's reagent [ $N, N$-diethyl-(1,1,2,3,3,3-hexafluoropropyl)amine] is a fluorinating hexafluoropropylamine used to convert alcohols into alkyl fluorides. On the other hand, it is also an example of model compound useful to probe conformational preferences using spectroscopic information from diastereotopic fluorines. Moreover, the possibility of experiencing both the generalized anomeric and gauche effects makes the Ishikawa's reagent an ideal choice to study the governing stereoelectronic interactions of the conformational equilibrium of organofluorine compounds. The conformational equilibrium of the Ishikawa's reagent was analyzed using $\mathrm{NMR}{ }^{3} J_{\mathrm{H}, \mathrm{F}}$ coupling constant data in different solvents, since the orientation of the diastereotopic fluorines relative to H-2 and F-2 changes with the medium. In nonpolar cyclohexane solvent, the preferred conformation experiences a weaker steric and electrostatic repulsion. The conformational behavior changes in the more polar pyridine solution, where the double fluorine gauche effect takes place, since F-2 is preferably gauche to both diastereotopic fluorines. An analysis of the rotation around the $\mathrm{N}-\mathrm{C}\left(\mathrm{F}_{2}\right)$ bond indicates the manifestation of anomeric interactions $\left(n_{\mathrm{N}} \rightarrow \sigma^{*} \mathrm{C}-\mathrm{F}\right)$, which can be demonstrated by means of ${ }^{19} \mathrm{~F}$ chemical shifts. The results were rationalized with the aid of theoretical calculations and natural bond orbital (NBO) analysis, allowing for the evaluation of competing steric, electrostatic and hyperconjugative interactions.
\end{abstract}

\section{Introduction}

The active species of Ishikawa's reagent $[N, N$-diethyl(1,1,2,3,3,3-hexafluoropropyl)amine, 1] [1] (Figure 1) has diastereotopic substituents (fluorines), which can be useful to provide conformational insights by using NMR spin-spin coupling constants (SSCCs), such as in methyl 2-fluoroesters [2], 3-fluoro-1,2-propanediol [3], 1-halo-2-propanols [4], enflurane [5], and 1-chloro-1,1-difluoro-2-pentanol [6]. This is possible due to an analogy with the Karplus curve that correlates the magnitude of vicinal ${ }^{3} J_{\mathrm{H}, \mathrm{H}}$ SSCCs with the dihedral angle between coupled nuclei [7]. According to this relationship, the 


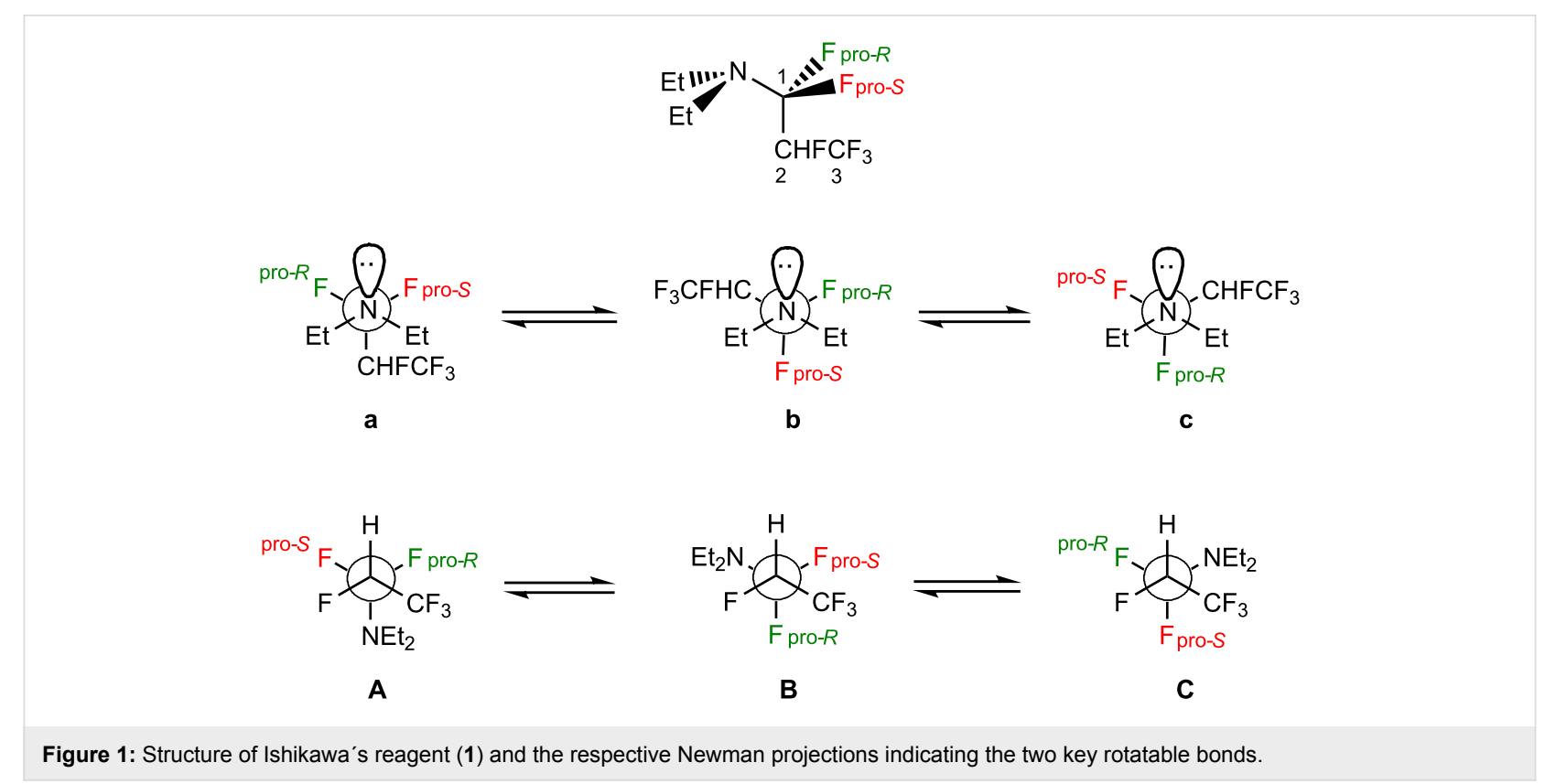

SSCC between antiperiplanar nuclei is larger than that observed between gauche nuclei. One-bond SSCCs $\left({ }^{1} J\right)$ can also provide relevant information on the conformations of a molecule. For example, the Perlin effect manifests in six-membered rings when ${ }^{1} J_{\mathrm{C}-\mathrm{Hax}}<{ }^{1} J_{\mathrm{C}-\mathrm{Heq}}[8,9]$. A similar effect on ${ }^{1} J_{\mathrm{C}-\mathrm{F}}$ has been observed on fluorinated six-membered rings and then called the (reverse) fluorine Perlin-like effect [10]. Despite some controversies on the origin of such effects [11-14], the anomeric-like interaction $n_{\mathrm{X}} \rightarrow \sigma^{*}{ }_{\mathrm{C}-\mathrm{H} / \mathrm{F}}(\mathrm{X}=$ electron donor atom, usually oxygen) seems to contribute to the magnitude of ${ }^{1} J_{\mathrm{C}-\mathrm{H} / \mathrm{F}}$, since the resonance structure originated from this interaction exhibits a longer and weaker $\mathrm{C}-\mathrm{H}_{\mathrm{ax}} / \mathrm{F}_{\mathrm{ax}}$ bond relative to $\mathrm{C}-\mathrm{H}_{\mathrm{eq}} / \mathrm{F}_{\mathrm{eq}}$, thus reducing ${ }^{1} J_{\mathrm{C}-\mathrm{Hax} / \mathrm{Fax}}$ relative to ${ }^{1} J_{\mathrm{C}-\mathrm{Heq} / \mathrm{Feq}}$. In turn, the incoming fluoride becomes magnetically more shielded than the fluorine not involved in such an interaction.

Because the positioning of neighboring groups relative to the diastereotopic fluorines ( $\mathrm{NEt}_{2}$ and $\mathrm{CHFCF}_{3}$ groups), the conformational preferences of Ishikawa's reagent molecule may be influenced by the generalized anomeric effect, as well as by the fluorine gauche effect. The former corresponds to a stabilizing effect originated from the electron delocalization from the nitrogen lone pair to an antiperiplanar $\mathrm{C}-\mathrm{F}$ antibonding orbital $\left(n_{\mathrm{N}} \rightarrow \sigma^{*} \mathrm{C}-\mathrm{F}\right)$, similarly to that observed for some pnictogen compounds and similar systems [15-18]. In turn, the fluorine gauche effect may result from the gauche orientation between F-1 and F-2, which is sterically and electrostatically disfavored, but it is stabilized by $\sigma_{\mathrm{C}-\mathrm{H} / \mathrm{C}-\mathrm{C}} \rightarrow \sigma^{*} \mathrm{C}-\mathrm{F}$ hyperconjugative interactions [19-23]. Recently, electrostatic polarization, on the basis of the so-called interacting quantum atoms (IQA) method, has been claimed as the origin of the gauche effect [24]. These effects have strongly influenced mechanisms of hydrogen exchange and the spectroscopic behavior of a variety of systems [25]; the respective fluorine scenario would then be worth to evaluate.

It is worth mentioning, however, that the relative and interchangeable orientation of the atoms in a molecule (conformations) is dependent on the medium; while only intramolecular interactions drive the conformational stability of a molecule in the vacuum, the solvent polarity plays a significant role in the condensed phase. Thus, it is appropriate to study the conformations of Ishikawa's reagent in different media, of low and high polarity. This is a challenging task, since the conformational analysis of flexible acyclic organic compounds using NMR SSCCs is more complex than the study of six-membered cyclic compounds, which usually exhibit only two conformations as the result of chair interconversion [26].

\section{Results and Discussion}

The preferred conformation along the $\mathrm{H}-\mathrm{C} 2-\mathrm{C} 1-\mathrm{F}$ fragment in 1 was first analyzed using ${ }^{3} J_{\mathrm{H}, \mathrm{F}(\text { pro- } S / R)} \mathrm{SSCC}$ data, since such an NMR parameter is sensitive to this dihedral angle according to a Karplus-like shape [27], while its sign is subjected to other effects [28]. Also, the observed ${ }^{3} J_{\mathrm{H}, \mathrm{F} \text { (pro-S/R) }}$ values (Table 1) are expected to be dependent on the medium, because the conformers of $\mathbf{1}$ are anticipated to have different molecular dipole moments and, consequently, the conformer populations are expected to change with the solvent polarity [29]. Indeed, the ${ }^{1} \mathrm{H}$ NMR outcomes in $\mathrm{C}_{6} \mathrm{D}_{12}$ (dielectric constant $\varepsilon=2.2$ ), $\mathrm{CDCl}_{3}(\varepsilon=4.8)$ and $\mathrm{C}_{5} \mathrm{D}_{5} \mathrm{~N}(\varepsilon=12.4)$ solutions are informative on the rotation of $\mathrm{H}-\mathrm{C} 2-\mathrm{C} 1-\mathrm{F}$ and conformational equilib- 
rium in 1. Some more polar solvents, e.g., MeCN and DMSO, were found to convert Ishikawa's reagent into an amide; therefore, they were not further studied.

Table 1: Experimental coupling constants $(\mathrm{Hz})$ for 1.

\begin{tabular}{lllll} 
Solvent & ${ }^{2} J_{\mathrm{H}, \mathrm{F}}$ & ${ }^{3} J_{\mathrm{H}, \mathrm{Fpro}-R}$ & ${ }^{3} J_{\mathrm{H}, \text { Fpro-S }}$ & ${ }^{3} J_{\mathrm{H}, \mathrm{F}-3}$ \\
\hline $\mathrm{C}_{6} \mathrm{D}_{12}$ & 44.46 & 11.69 & 3.53 & 5.89 \\
$\mathrm{CDCl}_{3}$ & 44.06 & 11.72 & 4.04 & 5.92 \\
$\mathrm{C}_{5} \mathrm{D}_{5} \mathrm{~N}$ & 42.34 & 11.99 & 6.00 & 6.00
\end{tabular}

In nonpolar solution $\left(\mathrm{C}_{6} \mathrm{D}_{12}\right)$, a $d d d q$ split pattern appears for $\mathrm{H}-2$ owing to a large ${ }^{2} J_{\mathrm{HF}}$ of $44.46 \mathrm{~Hz}$, two doublets (11.69 and $3.53 \mathrm{~Hz}$ ) due to couplings with the diastereotopic fluorines, and a quartet of $5.89 \mathrm{~Hz}$ due to the coupling with $\mathrm{CF}_{3}$ fluorines (Figure 2). Considering a Karplus-like curve for ${ }^{3} J_{\mathrm{H}, \mathrm{F}} \mathrm{SSCCs}$ [27], the magnitude of the ${ }^{3} J_{\mathrm{H}, \mathrm{F}(\text { pro-S/R) }} \mathrm{SSCCs}$ gives insight into the orientation of the $\mathrm{H}-\mathrm{C} 2-\mathrm{C} 1-\mathrm{F}$ dihedral angles, because the larger value $(11.69 \mathrm{~Hz})$ indicates a dominant anti orientation for this moiety, while the smaller SSCC $(3.53 \mathrm{~Hz})$ would be due to a gauche orientation. Accordingly, a dominant contributing conformation regarding the $\mathrm{H}-\mathrm{C} 2-\mathrm{C} 1-\mathrm{F}$ dihedral angle would be expected to be either $\mathbf{1 B}$ or $\mathbf{1 C}$.

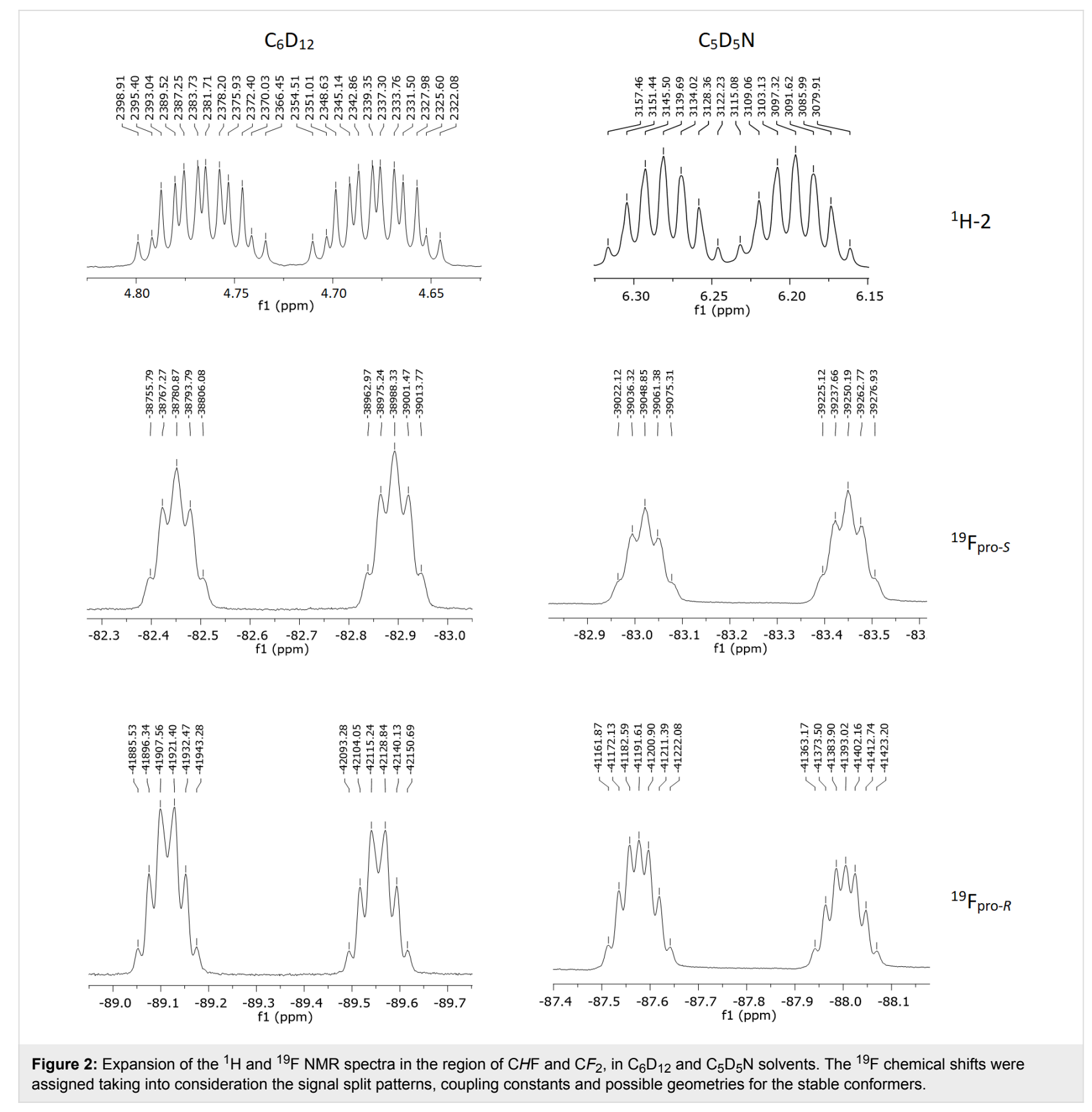


Moreover, there is a subtle solvent dependence of ${ }^{3} J_{\mathrm{H}, \mathrm{F}(\text { pro- } S / R)}$, indicating that the conformational equilibrium of $\mathbf{1}$ changes on going from cyclohexane (nonpolar) to pyridine (polar) solution. According to the calculated molecular dipole moments for the possible conformers of $\mathbf{1}$ (Table 2), a significant interplay of conformers $\mathbf{1 B}$ and $\mathbf{1 C}$ is not expected when the solvent varies, because of their similar molecular dipole moments. In turn, the populations of conformer $\mathbf{1 A}$ are not prone to increase by increasing the solvent polarity, because of their smaller molecular dipole moments compared to $\mathbf{1 B}$ and 1C. So, the observed changes in ${ }^{3} J_{\mathrm{H}, \mathrm{F}(\text { pro- } S / R)}$ with the solvent is due to a shift from 1A towards 1B or 1C. According to the Karplus curve, conformers $\mathbf{1 A}$ are not anticipated to have significantly different ${ }^{3} J_{\mathrm{H}, \mathrm{F}(1)} \mathrm{SSCCs}$, since both diastereotopic fluorines are gauche to H-2. However, SSCC calculations (Supporting Information File 1) show that conformers $\mathbf{1 A b}$ and $\mathbf{1 A c}$ exhibit

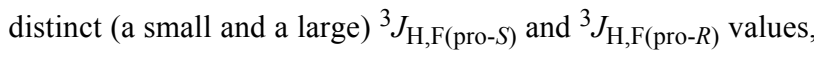
probably as a result of the generalized anomeric effect $n_{\mathrm{N}} \rightarrow$ $\sigma^{*} \mathrm{C}-\mathrm{F}$ that affects the electron density along the $\mathrm{C} 1-\mathrm{F}$ bond; a smaller ${ }^{3} J_{\mathrm{H}, \mathrm{F}(1)}$ is expected as a $\mathrm{C} 1-\mathrm{F}$ bond is longer and weaker. Because conformer $\mathbf{1 A c}$ is of very high energy and, therefore, non-populated (Table 2), the larger ${ }^{3} J_{\mathrm{H}, \mathrm{F}(1)} \mathrm{SSCC}$ in

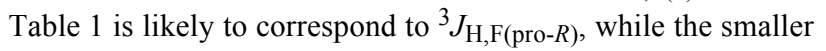
one corresponds to ${ }^{3} J_{\mathrm{H}, \mathrm{F}(\text { pro- } S \text { ) }}$. Since the large ${ }^{3} J_{\mathrm{H}, \mathrm{F} \text { (pro- } R \text { ) }}$ SSCC is practically insensitive to solvent changes, while ${ }^{3} J_{\mathrm{H}, \mathrm{F}(\text { pro-S })}$ increases on going from $\mathrm{C}_{6} \mathrm{D}_{12}$ to $\mathrm{C}_{5} \mathrm{D}_{5} \mathrm{~N}$ solution (from $3.53 \mathrm{~Hz}$ in cyclohexane solution to $6.00 \mathrm{~Hz}$ in pyridine solution), it follows that the above $\mathbf{1 A}$ conformation shifts toward $\mathbf{1 C}\left(\mathrm{F}_{\text {pro- } R}\right.$ anti in $\mathbf{1 B}$ and gauche in $\mathbf{1 C}$ relative to $\mathrm{H}-2$, while $\mathrm{F}_{\text {pro- } S}$ is gauche in $\mathbf{1 B}$ and anti in $\mathbf{1 C}$ ). The ${ }^{3} J_{\mathrm{F}, \mathrm{F}} \mathrm{SSCC}$ does not follow a Karplus-like shape, due to changes in the Fermi contact term with the rotation around the $\mathrm{F}-\mathrm{C}-\mathrm{C}-\mathrm{F}$ dihedral angle that even changes the sign [30]; so, the breakdown of the Karplus-like curve and a possible influence of the anomeric effect make this SSCC of little diagnostic value for probing the conformations of $\mathbf{1}$. An intermediate conformational behavior is calculated in chloroform solution, because this solvent has a larger dielectric constant than cyclohexane and a smaller value than pyridine, but the experimental ${ }^{3} J_{\mathrm{H}, \mathrm{F}(1)}$ obtained in $\mathrm{CDCl}_{3}$ suggests that the conformers population in this solvent is similar to that observed in cyclohexane solution. Thus, further discussion will consider only cyclohexane and pyridine solvents.

The generalized anomeric effect (due to the $n_{\mathrm{N}} \rightarrow \sigma^{*} \mathrm{C}-\mathrm{F}$ hyperconjugation) can be explored for assertion of the $\mathrm{C}-\mathrm{N}-\mathrm{C}-\mathrm{F}$ dihedral angle, which contributes to enhance the fluoride character of the fluorine involved in such interaction. Because of the negative charge on the fluorine in the resonance structure derived from the generalized anomeric effect, a shielding effect is expected for this fluorine. The ${ }^{19} \mathrm{~F}$ NMR assignment of the diastereotopic fluorines was possible considering the ${ }^{3} J_{\mathrm{H}, \mathrm{F}(1)}$ SSCC earlier reported, and comparing the ${ }^{19} \mathrm{~F}$ and ${ }^{19} \mathrm{~F}\left\{{ }^{1} \mathrm{H}\right\}$ NMR experiments: the more shielded diastereotopic fluorine corresponds to $\mathrm{F}_{\text {pro-S}}$, thus yielding $\mathbf{1 b}$ as the dominant conformation. Such a shielding effect decreases on going from cyclohexane $(-89.4 \mathrm{ppm})$ to pyridine solution $(-87.8 \mathrm{ppm})$, as the result of a conformational change towards $1 \mathrm{a}$ or $1 \mathrm{c}$. Since a slight shielding effect is observed on $\mathrm{F}_{\text {pro- } R}$ on going from cyclohexane to pyridine solution (from $-82.7 \mathrm{ppm}$ to $-83.2 \mathrm{ppm}$ ), an increase in the 1c conformation is then expected. Because of the rapid relaxation and the subsequent lack of ${ }^{13} \mathrm{C}-1$ signal, the fluorine Perlin effect could not be probed (although the calculated values can be checked in Supporting Information File 1). However, from the NMR results, in general, both $\mathbf{1 A b}$ and $\mathbf{1 C c}$ were found to be dominant conformations of the conformational equilibrium of the Ishikawa's reagent. In addition, this equilibrium shifts from $\mathbf{1 A b}$ to $\mathbf{1 C c}$ when increasing the solvent polarity. These findings are in complete agreement with the conformational energy data provided

\begin{tabular}{|c|c|c|c|c|c|c|}
\hline \multirow[t]{2}{*}{ Conf. } & \multicolumn{2}{|c|}{ Cyclohexane } & \multicolumn{2}{|l|}{ Chloroform } & \multicolumn{2}{|l|}{ Pyridine } \\
\hline & $G^{0}{ }_{\text {rel }}(\%)$ & $\mu$ & $G^{0}{ }_{\text {rel }}(\%)$ & $\mu$ & $G^{0}{ }_{\text {rel }}(\%)$ & $\mu$ \\
\hline $1 \mathrm{Aa}$ & $1.5(3)$ & 1.6 & $1.5(3)$ & 1.7 & $1.6(4)$ & 1.8 \\
\hline $1 \mathrm{Ab}$ & $0.0(40)$ & 2.1 & $0.4(20)$ & 2.2 & $0.9(15)$ & 2.3 \\
\hline $1 \mathrm{Ac}$ & $3.9(0)$ & 2.5 & $3.8(0)$ & 2.6 & $4.6(0)$ & 2.7 \\
\hline $1 \mathrm{Ba}$ & $1.7(2)$ & 4.2 & $1.6(2)$ & 4.6 & $2.0(2)$ & 4.8 \\
\hline $1 \mathrm{Bb}$ & $0.5(17)$ & 4.3 & $0.3(21)$ & 4.6 & $1.0(12)$ & 4.8 \\
\hline $1 \mathrm{Bc}$ & $0.7(13)$ & 4.5 & $0.5(17)$ & 4.9 & $2.4(1)$ & 5.2 \\
\hline $1 \mathrm{Ca}$ & $4.2(0)$ & 4.1 & $3.4(0)$ & 4.5 & $4.0(0)$ & 4.7 \\
\hline $1 \mathrm{Cb}$ & $4.0(0)$ & 4.0 & $3.9(0)$ & 4.3 & $4.2(0)$ & 4.5 \\
\hline $1 \mathrm{Cc}$ & $0.3(24)$ & 4.2 & $0.0(37)$ & 4.6 & $0.0(66)$ & 4.9 \\
\hline
\end{tabular}


in Table 2, which were obtained from high level DFT calculations (1Cb is not a minimum-energy conformer). The DFT results are also consistent with ab initio MP2 electronic energies (Supporting Information File 1).

Opposite to the expectation of a double fluorine gauche effect $\left(\sigma_{\mathrm{C}-\mathrm{H} / \mathrm{C}-\mathrm{C}} \rightarrow \sigma^{*} \mathrm{C}-\mathrm{F}\right)$ [19-23] as ruling mechanism of the conformational stability of $\mathbf{1}$, the $\mathbf{1} \mathbf{A b}$ conformer appears as the main conformer in a nonpolar medium. In part, the hyperconjugative interaction above (which is possible in $\mathbf{1 B}$ and $\mathbf{1 C}$ conformers) is somewhat counterbalanced by an $\sigma_{\mathrm{C}-\mathrm{H}} \rightarrow \sigma^{*} \mathrm{C}-\mathrm{N}$ interaction in $\mathbf{1 A}$, since $\sigma^{*} \mathrm{C}-\mathrm{N}$ is also a good electron acceptor orbital (see NBO energies in Table 3). In addition, this conformation avoids exceedingly strong dipolar repulsions due to two $\mathrm{C}-\mathrm{F} / \mathrm{C}-\mathrm{F}$ Coulombic contacts, such as in $\mathbf{1 C}$. In turn, the double gauche effect (in which F-2 is gauche to both diastereotopic fluorines) takes place in a more polar solution (due to 1C), as the dipolar repulsion between the vicinal fluorines is attenuated by the polar solvent, while the highly stabilizing hyperconjugative interactions are evidenced.

\section{Conclusion}

$N, N$-Diethyl-(1,1,2,3,3,3-hexafluoropropyl)amine (1) experiences the generalized anomeric effect in both nonpolar and polar solvents and, therefore, the $n_{\mathrm{N}} \rightarrow \sigma^{*} \mathrm{C}-\mathrm{F}$ hyperconjugative interaction plays a determinant role for the rotation around the $\mathrm{N}-\mathrm{C}\left(\mathrm{F}_{2}\right)$ bond in all tested media. However, the conformers capable of maximally performing the fluorine gauche effect, which is widely known to be due to an antiperiplanar

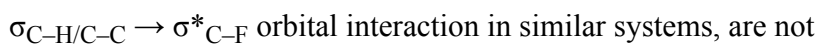
dominant in cyclohexane solution. Such an effect is actually manifested totally (as a double gauche effect, due to the gauche orientation of F-2 relative to both diastereotopic fluorines) in a polar solvent, where the dipolar repulsion is attenuated, and the gauche effect interactions then override the repulsive forces. Because of the significant difference in the molecular dipole moments for the conformers of $\mathbf{1}$, their populations were sensitive to solvent changes. Since the vicinal ${ }^{3} J_{\mathrm{H} 2, \mathrm{~F} 1}$ spin-spin coupling constants were found to be conformation-dependent, as well as the ${ }^{19} \mathrm{~F}$ chemical shifts, these NMR parameters provided detailed account on the $\mathrm{H}-\mathrm{C} 2-\mathrm{C} 1-\mathrm{F}$ dihedral angle as the solvent varied.

\section{Experimental and Computational Details}

$N, N$-Diethyl-(1,1,2,3,3,3-hexafluoropropyl)amine (1) was commercially available (90\% purity) and used without further purification. The NMR spectra were acquired at 400.2 or 499.9 MHz for ${ }^{1} \mathrm{H}, 470.3 \mathrm{MHz}$ for ${ }^{19} \mathrm{~F}$, and $125.7 \mathrm{MHz}$ for ${ }^{13} \mathrm{C}$, from ca. $10 \mathrm{mg} \mathrm{mL}^{-1}$ solutions in $\mathrm{C}_{6} \mathrm{D}_{12}, \mathrm{CDCl}_{3}$ and $\mathrm{C}_{5} \mathrm{D}_{5} \mathrm{~N}$ solvents. The geometries for the conformers of 1 were fully optimized (including frequency calculations) at the $\omega \mathrm{B} 97 \mathrm{X}-\mathrm{D} / 6-$ $311++G(d, p)$ level [31,32], which includes some empirical

\begin{tabular}{|c|c|c|c|c|c|c|c|c|c|}
\hline Interaction & $1 \mathrm{Aa}$ & $1 \mathrm{Ab}$ & $1 \mathrm{Ac}$ & $1 \mathrm{Ba}$ & $1 \mathrm{Bb}$ & 1Bc & $1 \mathrm{Ca}$ & $1 \mathrm{Cb}$ & $1 \mathrm{Cc}$ \\
\hline$n_{\mathrm{N}} \rightarrow \sigma^{*} \mathrm{C}-\mathrm{F}($ pro- $R$ ) & $\begin{array}{c}4.0 \\
(4.0)\end{array}$ & $\begin{array}{c}3.4 \\
(3.6)\end{array}$ & $\begin{array}{l}- \\
(-)\end{array}$ & $\begin{array}{c}4.8 \\
(4.8)\end{array}$ & $\begin{array}{c}5.1 \\
(5.6)\end{array}$ & $\begin{array}{c}34.4 \\
(36.6)\end{array}$ & $\begin{array}{c}17.4 \\
(18.1)\end{array}$ & $\begin{array}{c}0.5 \\
-\end{array}$ & $\begin{array}{c}34.2 \\
(35.1)\end{array}$ \\
\hline$n_{\mathrm{N}} \rightarrow \sigma^{*} \mathrm{C}-\mathrm{F}$ (pro-S) & $\begin{array}{c}15.7 \\
(16.0)\end{array}$ & $\begin{array}{c}35.2 \\
(36.6)\end{array}$ & - & $\begin{array}{c}13.1 \\
(13.6)\end{array}$ & $\begin{array}{c}36.7 \\
(38.0)\end{array}$ & $\begin{array}{c}9.3 \\
(10.3)\end{array}$ & $\begin{array}{c}2.0 \\
(2.1)\end{array}$ & $\begin{array}{c}23.0 \\
(24.6)\end{array}$ & $\begin{array}{c}2.3 \\
(2.7)\end{array}$ \\
\hline$n_{\mathrm{N}} \rightarrow \sigma^{*}{ }_{\mathrm{C} 1-\mathrm{C} 2}$ & $\begin{array}{c}17.7 \\
(17.8)\end{array}$ & $\begin{array}{c}3.7 \\
(3.6)\end{array}$ & - & $\begin{array}{c}16.0 \\
(16.2)\end{array}$ & $\begin{array}{c}2.8 \\
(2.7)\end{array}$ & $\begin{array}{c}1.4 \\
(1.3)\end{array}$ & $\begin{array}{c}14.7 \\
(15.0)\end{array}$ & $\begin{array}{c}8.3 \\
(8.5)\end{array}$ & $\begin{array}{c}4.0 \\
(3.8)\end{array}$ \\
\hline$\sigma_{\mathrm{C}-\mathrm{H}} \rightarrow \sigma^{*} \mathrm{C}-\mathrm{F}($ pro- $R)$ & $\begin{array}{c}1.0 \\
(1.0)\end{array}$ & $\begin{array}{c}1.8 \\
(1.8)\end{array}$ & $\begin{array}{c}0.6 \\
(0.5)\end{array}$ & $\begin{array}{c}4.6 \\
(4.7)\end{array}$ & $\begin{array}{c}4.5 \\
(4.6)\end{array}$ & $\begin{array}{c}4.2 \\
(4.3)\end{array}$ & $\begin{array}{c}0.9 \\
(0.9)\end{array}$ & $\begin{array}{c}1.4 \\
(1.4)\end{array}$ & $\begin{array}{c}0.9 \\
(0.9)\end{array}$ \\
\hline$\sigma_{\mathrm{C}-\mathrm{H}} \rightarrow \sigma^{*} \mathrm{C}-\mathrm{F}($ pro-S) & $\begin{array}{c}0.9 \\
(0.9)\end{array}$ & $\begin{array}{c}0.5 \\
(0.5)\end{array}$ & $\begin{array}{c}1.4 \\
(1.5)\end{array}$ & $\begin{array}{c}0.8 \\
(0.7)\end{array}$ & $\begin{array}{c}1.2 \\
(1.1)\end{array}$ & - & $\begin{array}{c}4.6 \\
(4.7)\end{array}$ & $\begin{array}{c}4.8 \\
(4.8)\end{array}$ & $\begin{array}{c}4.2 \\
(4.1)\end{array}$ \\
\hline$\sigma_{\mathrm{C}-\mathrm{H}} \rightarrow \sigma^{*} \mathrm{C}-\mathrm{N}$ & $\begin{array}{c}3.6 \\
(3.7)\end{array}$ & $\begin{array}{c}4.0 \\
(4.1)\end{array}$ & $\begin{array}{c}4.6 \\
(4.5)\end{array}$ & - & - & $\begin{array}{c}0.5 \\
(0.5)\end{array}$ & - & - & - \\
\hline$\sigma_{\mathrm{C}-\mathrm{F} 2} \rightarrow \sigma^{*} \mathrm{C}-\mathrm{F}($ pro- $R)$ & $\begin{array}{c}1.3 \\
(1.4)\end{array}$ & $\begin{array}{c}1.2 \\
(1.2)\end{array}$ & $\begin{array}{c}0.7 \\
(0.7)\end{array}$ & $\frac{-}{(-)}$ & - & - & $\begin{array}{l}- \\
(-)\end{array}$ & $(-)$ & - \\
\hline$\sigma_{\mathrm{C}-\mathrm{F} 2} \rightarrow \sigma^{*} \mathrm{C}-\mathrm{F}$ (pro-S) & $\frac{-}{(-)}$ & $\begin{array}{l}- \\
(-)\end{array}$ & $\begin{array}{l}- \\
(-)\end{array}$ & $\begin{array}{c}1.4 \\
(1.5)\end{array}$ & $\begin{array}{c}1.3 \\
(1.4)\end{array}$ & $\begin{array}{c}1.5 \\
(1.5)\end{array}$ & $\begin{array}{l}- \\
(-)\end{array}$ & $\begin{array}{l}- \\
(-)\end{array}$ & $(-)$ \\
\hline$\sigma_{\mathrm{C}-\mathrm{F} 2} \rightarrow \sigma^{*} \mathrm{C}-\mathrm{N}$ & $(-)$ & $(-)$ & $\begin{array}{c}0.6 \\
(0.6)\end{array}$ & - & - & - & $\begin{array}{c}1.2 \\
(1.3)\end{array}$ & $\begin{array}{c}1.4 \\
(1.4)\end{array}$ & $\begin{array}{c}1.5 \\
(1.5)\end{array}$ \\
\hline$\sigma_{\mathrm{C} 2-\mathrm{C} 3} \rightarrow \sigma^{*} \mathrm{C}-\mathrm{F}($ pro- $R$ ) & $\frac{-}{(-)}$ & $\begin{array}{l}- \\
(-)\end{array}$ & $\begin{array}{l}- \\
(-)\end{array}$ & 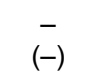 & $\begin{array}{c}0.7 \\
(0.7)\end{array}$ & $(-)$ & $\begin{array}{c}1.8 \\
(1.8)\end{array}$ & $\begin{array}{c}1.6 \\
(1.6)\end{array}$ & $\begin{array}{c}2.2 \\
(2.2)\end{array}$ \\
\hline$\sigma_{\mathrm{C}-\mathrm{C} 3} \rightarrow \sigma^{*} \mathrm{C}-\mathrm{F}$ (pro-S) & $\begin{array}{c}1.6 \\
(1.6)\end{array}$ & $\begin{array}{c}2.0 \\
(2.0)\end{array}$ & $\begin{array}{c}1.2 \\
(1.3)\end{array}$ & - & $(-)$ & $\begin{array}{c}0.7 \\
(0.7)\end{array}$ & - & $(-)$ & - \\
\hline$\sigma_{\mathrm{C}-\mathrm{C} 3} \rightarrow \sigma^{*} \mathrm{C}-\mathrm{N}$ & $(-)$ & $\frac{-}{(-)}$ & $\frac{-}{(-)}$ & $\begin{array}{c}1.5 \\
(1.5)\end{array}$ & $\begin{array}{c}1.8 \\
(1.8)\end{array}$ & $\begin{array}{c}1.7 \\
(1.7)\end{array}$ & $(-)$ & $(-)$ & $(-)$ \\
\hline
\end{tabular}


dispersion effects. The calculations were carried out considering both the gas phase and implicit solvation, according to the polarizable continuum model [33]. The nine possible conformers were selected after a previous screening from 81 structures, which differed by the orientation of the $N$-ethyl groups. Subsequent natural bond orbital (NBO) [34] analyses at the $\omega \mathrm{B} 97 \mathrm{X}-\mathrm{D} / 6-311++\mathrm{G}(\mathrm{d}, \mathrm{p})$ level $[31,32]$ were performed to obtain the second-order perturbation energies of donor-acceptor interactions. This same level of theory was employed for the chemical shift and SSCC calculations.

\section{Supporting Information}

\section{Supporting Information File 1}

Standard coordinates for the geometries of conformers of $\mathbf{1}$,

NMR spectra and tables containing calculated

spectroscopic data.

[https://www.beilstein-journals.org/bjoc/content/

supplementary/1860-5397-15-44-S1.pdf]

\section{Acknowledgements}

The authors are grateful to FAPEMIG (APQ-00383/15 and PPM-00344/17), PRP/FAEPEX (2967/17) and FAPESP for the financial support of this research, as well as to Coordenação de Aperfeiçoamento de Pessoal de Nível Superior - CAPES for the studentships (to L. A. F. A. and L. A. Z.), FAPESP (2018/ 03910-1) for a fellowship (to R. A. C), and to the Conselho Nacional de Desenvolvimento Científico e Tecnológico - CNPq for a fellowship (to M. P. F.).

\section{ORCID ${ }^{\circledR}$ iDs}

Lucas A. Zeoly - https://orcid.org/0000-0003-2111-3904

Rodrigo A. Cormanich - https://orcid.org/0000-0001-7659-1749

Matheus P. Freitas - https://orcid.org/0000-0002-7492-1801

\section{References}

1. Takaoka, A.; Iwakiri, H.; Ishikawa, N. Bull. Chem. Soc. Jpn. 1979, 52, 3377-3380. doi:10.1246/bcsj.52.3377

2. Tormena, C. F.; Freitas, M. P.; Rittner, R.; Abraham, R. J. Phys. Chem. Chem. Phys. 2004, 6, 1152-1156. doi:10.1039/b311570d

3. Andrade, L. A. F.; Silla, J. M.; Duarte, C. J.; Rittner, R.; Freitas, M. P. Org. Biomol. Chem. 2013, 11, 6766-6771. doi:10.1039/c3ob41207e

4. Gonçalves, K. M. S.; Garcia, D. R.; Ramalho, T. C.; Figueroa-Villar, J. D.; Freitas, M. P. J. Phys. Chem. A 2013, 117, 10980-10984. doi:10.1021/jp408528j

5. Andrade, L. A. F.; Silla, J. M.; Stephens, S. L.; Marat, K.; da Cunha, E. F. F.; Ramalho, T. C.; van Wijngaarden, J.; Freitas, M. P. J. Phys. Chem. A 2015, 119, 10735-10742. doi:10.1021/acs.jpca.5b08087

6. Martins, F. A.; Zeoly, L. A.; Cormanich, R. A.; Freitas, M. P. Tetrahedron 2018, 74, 880-883. doi:10.1016/j.tet.2018.01.008
7. Karplus, M. J. Am. Chem. Soc. 1963, 85, 2870-2871. doi:10.1021/ja00901a059

8. Perlin, A. S.; Casu, B. Tetrahedron Lett. 1969, 10, 2921-2924. doi:10.1016/s0040-4039(01)88308-8

9. Juaristi, E.; Cuevas, G. Acc. Chem. Res. 2007, 40, 961-970. doi:10.1021/ar6000186

10. Silla, J. M.; Freitas, M. P.; Cormanich, R. A.; Rittner, R. J. Org. Chem. 2014, 79, 6385-6388. doi:10.1021/jo501025a

11. Cuevas, G.; Martínez-Mayorga, K.; Fernández-Alonso, M. d. C.; Jiménez-Barbero, J.; Perrin, C. L.; Juaristi, E.; López-Mora, N. Angew. Chem., Int. Ed. 2005, 44, 2360-2364. doi:10.1002/anie.200461583

12. Hernández-Lima, J. G.; Barquera-Lozada, J. E.; Cuevas, G.; Cortés-Guzmán, F. J. Comput. Chem. 2015, 36, 1573-1578. doi:10.1002/jcc.23965

13. Silla, J. M.; Freitas, M. P. J. Fluorine Chem. 2015, 172, 1-6. doi:10.1016/j.jluchem.2015.01.005

14. Silla, J. M.; Freitas, M. P. RSC Adv. 2016, 6, 74598-74603. doi:10.1039/c6ra10272g

15. Martins, L. E.; Freitas, M. P. J. Phys. Org. Chem. 2008, 21, 881-885. doi:10.1002/poc.1397

16. Irwin, J. J.; Ha, T.-K.; Dunitz, J. D. Helv. Chim. Acta 1990, 73, 1805-1817. doi:10.1002/hlca.19900730702

17. Christen, D.; Mack, H.-G.; Rüdiger, S.; Oberhammer, H. J. Am. Chem. Soc. 1996, 118, 3720-3723. doi:10.1021/ja954019r

18. Wiberg, K. B.; Bailey, W. F.; Lambert, K. M.; Stempel, Z. D. J. Org. Chem. 2018, 83, 5242-5255. doi:10.1021/acs.joc.8b00707

19. Goodman, L.; Gu, H.; Pophristic, V. J. Phys. Chem. A 2005, 109, 1223-1229. doi:10.1021/jp046290d

20. Souza, F. R.; Freitas, M. P.; Rittner, R. J. Mol. Struct.: THEOCHEM 2008, 863, 137-140. doi:10.1016/j.theochem.2008.06.003

21. Buissonneaud, D. Y.; van Mourik, T.; O'Hagan, D. Tetrahedron 2010, 66, 2196-2202. doi:10.1016/j.tet.2010.01.049

22. Freitas, M. P.; Bühl, M.; O'Hagan, D. Chem. Commun. 2012, 48, 2433-2435. doi:10.1039/c2cc17180e

23. Thiehoff, C.; Rey, Y. P.; Gilmour, R. Isr. J. Chem. 2017, 57, 92-100. doi:10.1002/ijch.201600038

24. Thacker, J. C. R.; Popelier, P. L. A. J. Phys. Chem. A 2018, 122, 1439-1450. doi:10.1021/acs.jpca.7b11881

25. Perrin, C. L. J. Org. Chem. 2017, 82, 819-838. doi:10.1021/acs.joc.6b02390

26. Eliel, E. L.; Wilen, S. H.; Mander, L. N. Stereochemistry of Organic Compounds; John Wiley \& Sons: New York, 1994.

27. San Fabián, J.; Guilleme, J. Chem. Phys. 1996, 206, 325-337. doi:10.1016/0301-0104(96)00032-8

28. Viesser, R. V.; Ducati, L. C.; Autschbach, J.; Tormena, C. F. Phys. Chem. Chem. Phys. 2016, 18, 24119-24128. doi:10.1039/c6cp04853f

29. Abraham, R. J.; Bretschneider, E. In Internal Rotation in Molecules; Orville-Thomas, W. J., Ed.; Academic Press: London, 1974.

30. Provasi, P. F.; Sauer, S. P. A. J. Chem. Theory Comput. 2006, 2 , 1019-1027. doi:10.1021/ct6000973

31. Chai, J.-D.; Head-Gordon, M. Phys. Chem. Chem. Phys. 2008, 10, 6615-6620. doi:10.1039/b810189b

32. Frisch, M. J.; Pople, J. A.; Binkley, J. S. J. Chem. Phys. 1984, 80, 3265-3269. doi:10.1063/1.447079

33. Tomasi, J.; Mennucci, B.; Cammi, R. Chem. Rev. 2005, 105, 2999-3094. doi:10.1021/cr9904009

34. Weinhold, F.; Landis, C. R. Discovering Chemistry with Natural Bond Orbitals; Wiley: Hoboken, 2012. doi:10.1002/9781118229101 


\section{License and Terms}

This is an Open Access article under the terms of the Creative Commons Attribution License (http://creativecommons.org/licenses/by/4.0). Please note that the reuse, redistribution and reproduction in particular requires that the authors and source are credited.

The license is subject to the Beilstein Journal of Organic Chemistry terms and conditions:

(https://www.beilstein-journals.org/bjoc)

The definitive version of this article is the electronic one which can be found at:

doi:10.3762/bjoc. 15.44 